\title{
Acoustic emission monitoring on Delhi quartzite under compressive loading
}

\author{
Prateek Negi and Tanusree Chakraborty \\ Indian Institute of Technology Delhi \\ New Delhi,India \\ negidynamic@gmail.com
}

\begin{abstract}
The acoustic emissions are the high frequency waves caused by the sudden release of energy from local points within a loaded rock specimen. In common terms these emissions can be related to the formation of microcracks within the rock structure. As the failure propagation in a brittle rock is very much associated with the formation of microcracks, the study of acoustic emissions has a great potential to understand the phenomenon of failure. The test was conducted on Delhi quartzite which is quite a brittle rock. The yield point of the rock specimen has been found more accurately.
\end{abstract}

Keywords-acoustic emission; brittle rock; Delhi Quartzite; emission counts.

\section{INTRODUCTION}

L.Obert and W.I. Duvall in the early 1930's discovered the stressed rocks produces sounds at different amplitude level. Initially those sounds were named "rock talk" but later on it opened the gates for a new method of analysis of rocks under stresses as acoustic emission technique [1]. Today it is being used as a tool in number of geotechnical applications. Not only rocks but other materials like ceramics, metals concrete etc. emits acoustic emissions (AE) on being deformed or stressed. Initial work on metals has begun around ten years after the first reporting of Obert and Duvall by Kaiser [2].

The failure of a rock is a complex phenomenon which is described conventionally using the stress - strain curve of a rock under unconfined compressive loading. The occurrence of $\mathrm{AE}$ is very much dependent on the various stages of the failure process like crack initiation and formation of macro cracks. HenceAE monitoring while stress, strain measurement is much more definitive in understanding the rock failure behaviourespecially for the brittle rocks. Researchers have developed new techniques for acquiring $\mathrm{AE}$ signature of rocks and have used them vastly in rock mechanics [3-7].

The uniaxial and triaxial compression tests can be performed to find out the peak strength of a rock which is a basic parameter in rock mechanics design. The two basic strength criteria used are linear Mohr-Coulomb failure criterion and the nonlinear Hoek-Brown failure criteria.The peak strength of a rock is not a unique property of the entire rock block. It depends on various factors of loading conditions also, like rate of loading [8]. Due to ductile behaviour, the brittle rocks like rock salt, shows creep deformation without developing fractures and micro-cracks up to a stress level called dilatancy boundary. [9]. Hence the AE emissions start occurring above the dilatancy boundary only. These small micro fractures join within themselves and forms, macrocracks later on.

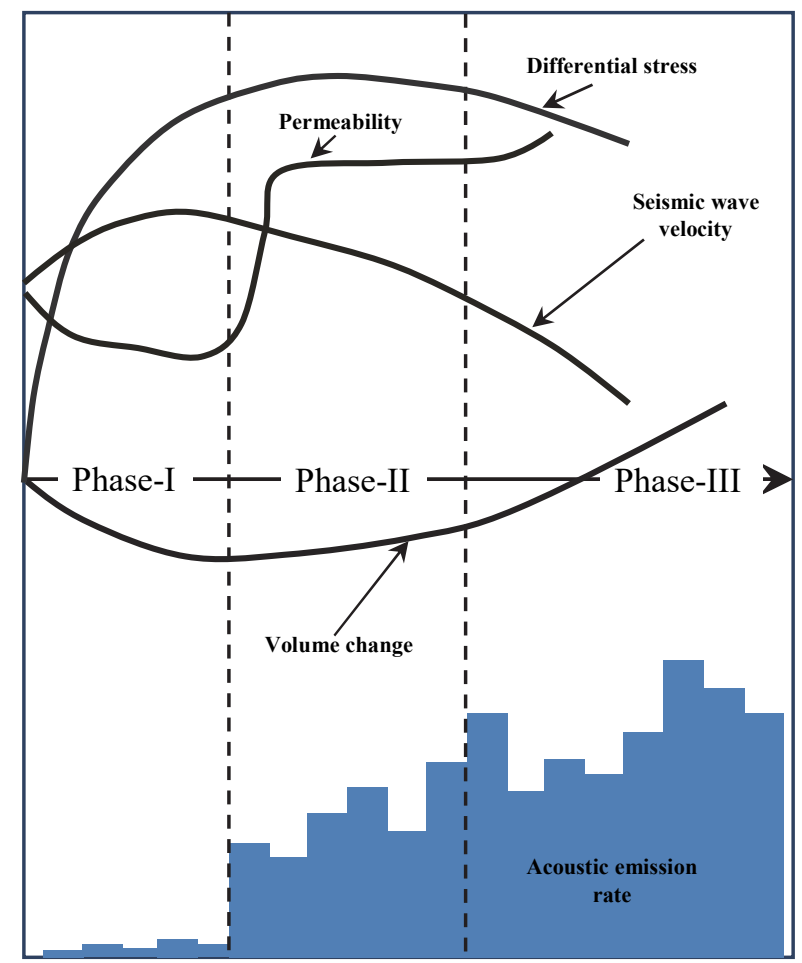

Fig. 1. Change in rock properties in a compression test [11].

Fig.1 shows the variation in rock properties while going through a compression test. The change in volume, AE rate, permeability and ultrasonic pulse velocity are shown with increase in the strain under constant strain rate. Phase I indicates towards the decrease in the volume due to elastic compression of the specimen without developing micro-cracks. Simultaneously, thisresult in decrease in the permeability and increase in the seismic wave velocity of the specimen. The volume of the specimen becomes constant at the end of this stage.

As soon as the testing enters phase II the AE starts occurring spontaneously in case of a brittle rock. This indicates the forming of new cracks and surfaces within the volume of the specimen. The interconnection of the newly developed fissures increases the permeability rapidly, but, the seismic 
velocity decreases. When the specimen reaches phase III, the $\mathrm{AE}$ rate and dilatancy increases suddenly. The cracks developed at this stage can be seen on the surface of the specimen just before the specimen breaks down completely. Permeabilty and the seismic velocity follow the same trend as in phase II. The sudden release of the strain energy in brittle rocks results in the explosion of the specimen.

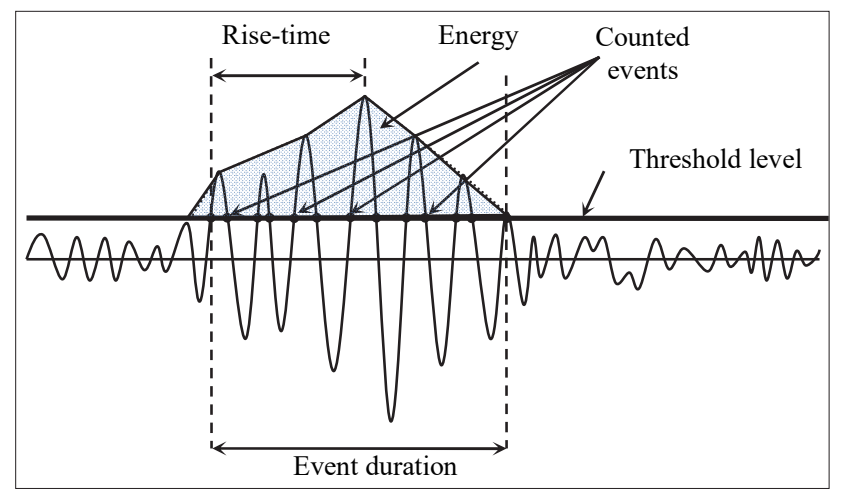

Fig. 2. A typical acoustic emission waveform. Source:www.vallen.de

The rock failure process can be associated with AE counts and rate [10]. An AE is a transient elastic wave of a varying bandwidth emitted from the development of any crack or micro-fracture within the volume of the material subjected to some loading. The shape and features of the AE wave signal depend upon the source event, medium, instrument response. The strain energy being stored in grains of the material due to applied stress is released rapidly in very small parts resulting in AE. It has been extensively studied in rock mechanics applications. Researchers have studied AE counts and AE rates scaled to the stress-strain plot of the specimen so as to get a better understanding of crack initiation and propagation subjected to the loading condition. There are some waveform parameters as shown in Fig. 2., such as peak amplitude, risetime, event duration and energy of the event. These parameters can classify each event as weak and strong.

\section{ROCK PROPERTIES}

Delhi quartzite is the extension of the Aravali hills and is the part of the Precambrian Delhi system [12]. The sample cored out were light grey in colour with some slight features of weathering like yellow and brown colour at the joints on the exposed surface. Quartz mineral is present dominantly from 85 to $95 \%$ with some other minerals like Biotite, Muscovite and Feldspars [13]. The basic physical and index properties were found in the laboratory conditions and are listed in the Table I. The specimens were prepared in the cylindrical form of L/D ratio two following the ISRM standards.

TABLE I. PHYSICAL AND INDEX PROPERTIES OF DELHI QUARTZITE

\begin{tabular}{|l|l|}
\hline Index properties & Values \\
\hline Specific gravity $(\mathrm{G})$ & 2.66 \\
\hline Dry density $(\rho d)$ & $2.59 \mathrm{~g} / \mathrm{cc}$ \\
\hline Saturated density & $2.60 \mathrm{~g} / \mathrm{cc}$ \\
\hline Void ratio $(\mathrm{e})$ & 0.02 \\
\hline Porosity (absolute) $(\eta \mathrm{a})$ & $1.97 \%$ \\
\hline Ultra sonic wave velocity (dry) & $5410 \mathrm{~m} / \mathrm{s}$ \\
\hline Unconfined compressive strength $(\sigma \mathrm{c})$ & $116 \mathrm{MPa}$ \\
\hline Modulus $(\mathrm{Ei})$ & $56.00 \mathrm{GPa}$ \\
\hline
\end{tabular}

The stress-strain curve recorded while performing the AE test is shown in the Fig. 3.

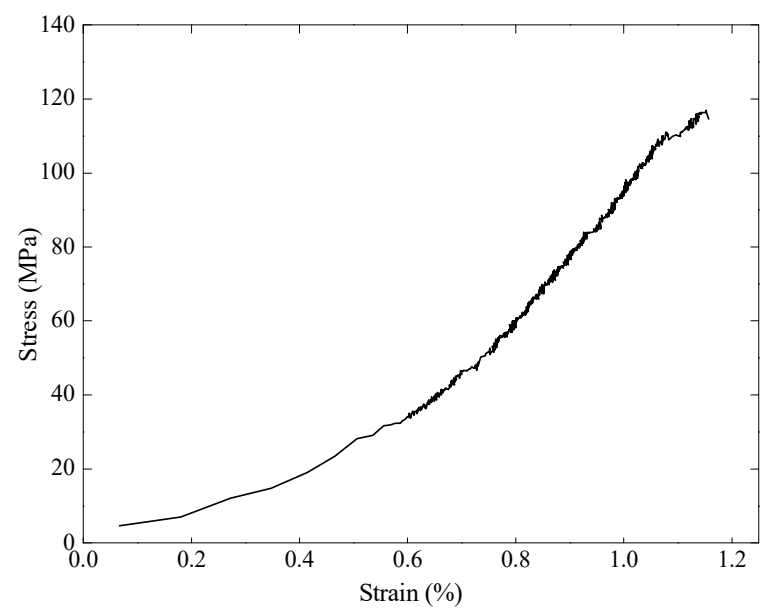

Fig. 3. Stress-Strain curve for Delhi Quartzite while testing

\section{ACOUSTIC SignALS}

The acoustic signals were recorded using piezo based acoustic transducers and the recorded data was analysed using MATLAB. The specimen was subjected to an unconfined compressive stress controlled loading. The rate of loading was $0.1 \mathrm{kN} / \mathrm{s}$. Fig.4. shows the recorded AE peaks between 850 to 935 seconds. The whole test war recorded for the complete 945 seconds. But, as there were very almost negligible events occurring before 850 seconds, the enlarged view of the above time band is only shown. The amplitudes were recorded relatively in the range of -1 to 1 , with a very high sampling rate. It can be seen that the major yielding events have occurred four times, releasing the large packets of strain energy stored. While, data analysis a threshold limit of 0.03 was selected to count the events as peaks which are occurring above it. The maximum noise level was in the range of 0.001 whereas; the recorded signal strength was in the range of 0.1 to 1 . This shows a very good signal to noise ratio of 100 to 1000 . It shows that the actual events recorded were very contrasting with respect to the ambient noise recorded by the transducers. There were 5452 events recorded above the threshold limit. All of the events are plotted cumulatively in Fig. 5.

It can be seen clearly that just after the 850th second, events started occurring spontaneously. This shows that the rock specimen has developed strains before this point of loading and then suddenly showed a brittle failure.

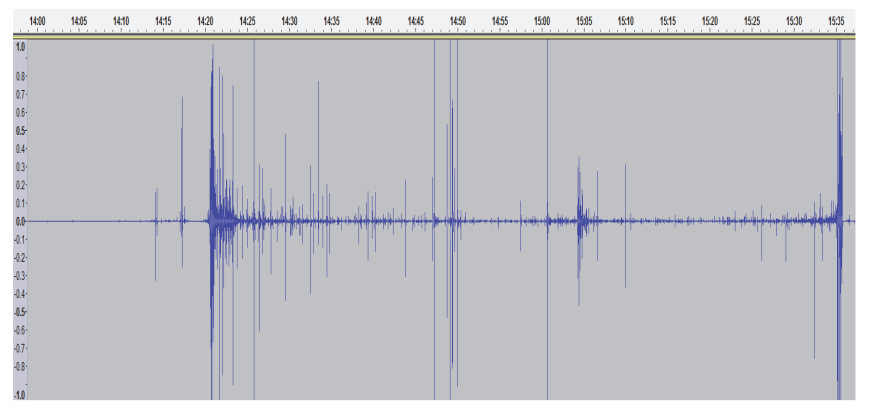

Fig. 4. AE peaks recorded between $850-935$ seconds 


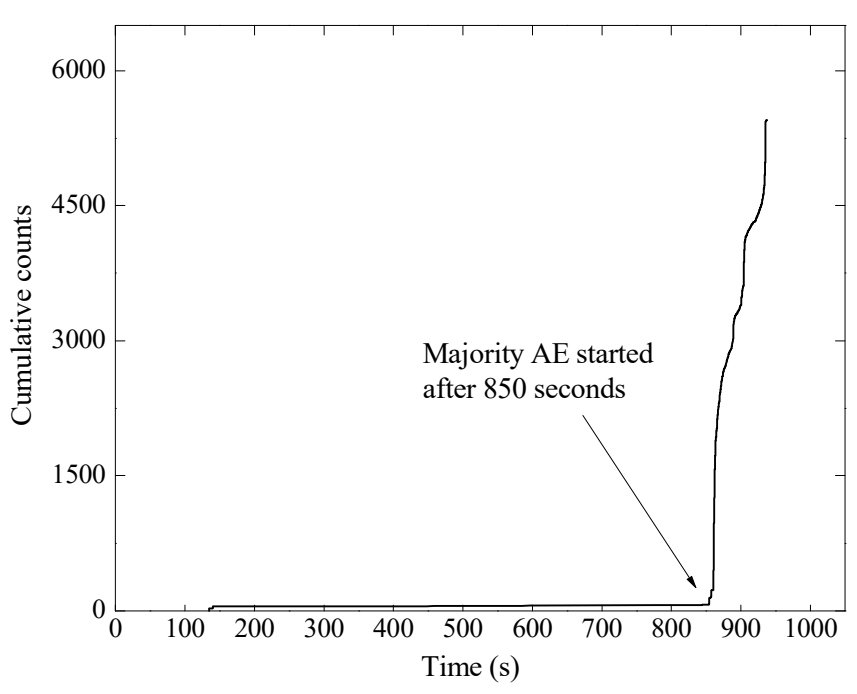

Fig. 5. Cumulative event counts recorded with respect to time.

\section{ANALYSIS AND INTERPRETATION}

The Fig.6. shows the complete stress-strain curve with the corresponding cumulative AE counts. For AE curve the x-axis is the running time of the test and $\mathrm{y}$-axis is thecumulative $\mathrm{AE}$ counts.

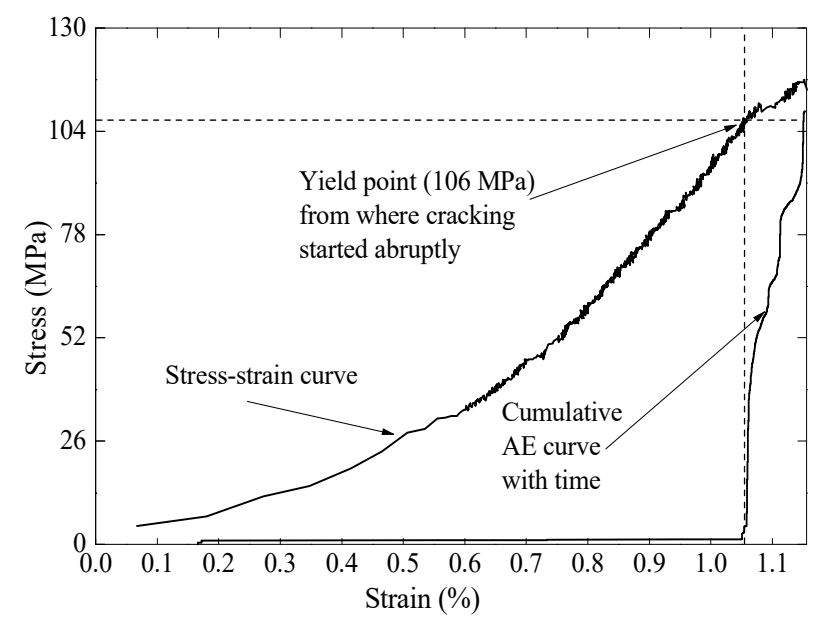

Fig. 6. Cumulative counts with the stress-strain plot.

At around $106 \mathrm{MPa}$ of stress, cracking started abruptly forming new surfaces within the specimen. This can be said as the yield point for the rock specimen. The initial part of the curve is non linear elastic. The maximum strain recorded was $1.15 \%$. The reason behind this large developed strain is the slightly weathering of the specimen. It can be observed well that after the yield point curve has changed its slope drastically.

The Fig.7.shows the relative energy of each even recorded in comparison to the smallest amount of event energy recorded. All the calculations have been made relatively instead of the absolute values so as to provide simplicity in the analysis. The energy has been plotted in a log scale with time in seconds. It can be clearly seen that the events were of different intensities ranging widely in the order of 1 to 105.The Fig. 8 . shows the enlarged view of time band $850-950$ seconds. It can be seen that the most of the events haveoccurred very simultaneously.

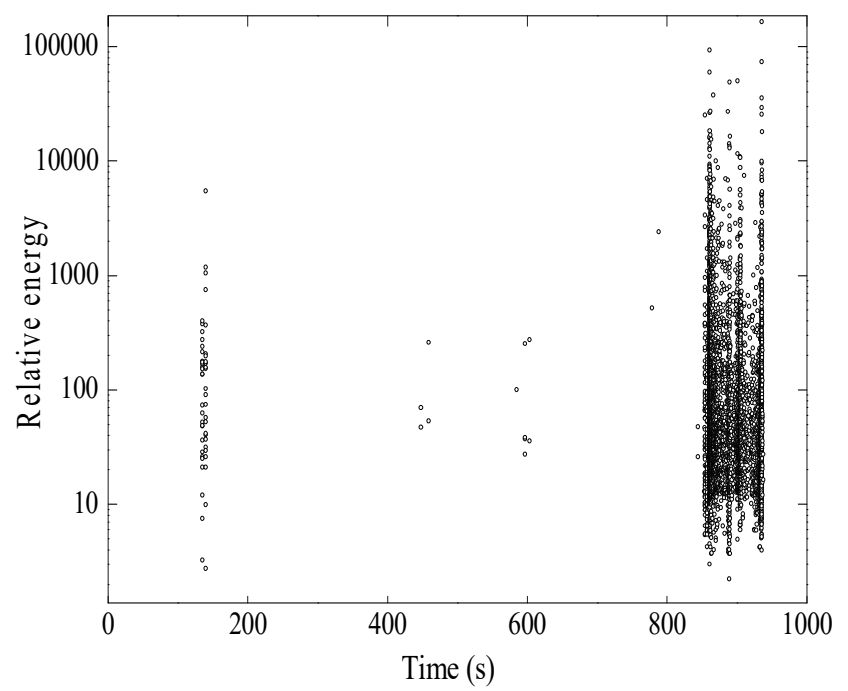

Fig. 7. Relative energy of every event with time $(0-100 \mathrm{sec})$

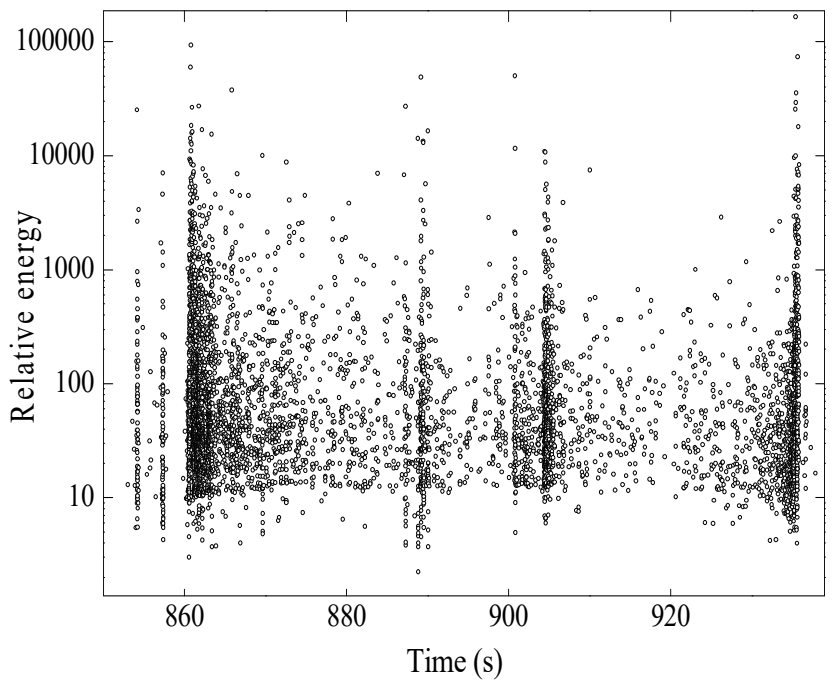

Fig. 8. Relative energy of every event with time (850-950 sec)

The clusters of energy points display the sudden release of strain energy.

\section{CONCLUSIONS}

The failure process of a brittle rock is significantly dependent on crack initiation and propagation. In the present paper the stress-strain behaviour of Delhi quartzite specimen has been studied using $\mathrm{AE}$ technique. The occurrence of emissions during the testing very much correlates with the previous stress history of the rock. The specimen has shown elasticity until the yielding in the form of formation of new cracks has not started. The total strain energy stored by the specimen seems to be released suddenly in the form of packets. Four such released packets can be seen easily in the energytime graph. The use of the $\mathrm{AE}$ technique in continuous monitoring of underground structures in brittle rocks is still in doubt. More number of testing at different strain rates is required to completely comment on the feasibility of the $\mathrm{AE}$ technique for the underground monitoring of brittle rocks. 


\section{REFERENCES}

[1] Obert, L. and Duvall, W., "Use of Subaudible Noises for the Prediction of Rock Bursts,Part II," RI 3654, U.S. Bureau of Mines, 1942.

[2] Kaiser, J., "Untersuchungen uber das Auftreten Gerauschen Beim Zugversuch," Arkivfur das Eisenhuttenwesen, Vol. 24, pp. 43-45, 1953.

[3] Eberhardt E, Stead D, Stimpson B. Quantifying progressive pre-peak brittlefracture damage in rock during uniaxial compression. International Journal ofRock Mechanics and Mining Science 1999;36:361-80.

[4] Cai M, Kaiser PK, Morioka H, Minami M, Maejima T, Tasaka Y, et al. FLAC/PFCcoupled numerical simulation of $\mathrm{AE}$ in large-scale underground excavations.

[5] International Journal of Rock Mechanics and Mining Science 2007;44:550-64.

[6] Cai M, Morioka H, Kaiser PK, Tasaka Y, Kurose H, Minami M, et al. Backanalysis of rock mass strength parameters using $\mathrm{AE}$ monitoring data. InternationalJournal of Rock Mechanics and Mining Science 2007;44(4):538-49.

[7] Moradian ZA, Ballivy G, Rivard P, Gravel C, Rousseau B. Evaluating damageduring shear tests of rock joints using acoustic emissions. International Journalof Rock Mechanics and Mining Science 2010;47:590-8.

[8] Martin, CD., "The strength of massive Lac du Bonnet granite around undergroundopenings," A Ph.D. thesis, University of Manitoba, Canada, 1993.

[9] Manthei, G., Eisenblätter, J., "Application of the Cluster Method on Acoustic Emission Events in aRock Salt Specimen". 30th European Conference on Acoustic Emission Testing \& 7th International Conference on Acoustic EmissionUniversity of Granada, 2012.

[10] Zhao, X.G., Cai , M., Wang, J., Ma,L.K. "Damage stress and acoustic emission characteristicsof the Beishan granite", International Journal of Rock Mechanics \& Mining Sciences 64 pp. 258-269, 2013.

[11] Popp T, Kern H, Schulze, O., "Permeation and development of dilatancy in rock salt.In: Cristescu ND, Hardy HR Jr, Simionescu RO (eds.)," Basic and Applied Salt Mechanics;Proc. of the 5th Conference on the Mechanical Behavior of Salt, Bukarest 1999, Balkema, pp. 95-124, 2002.

[12] Krishnan, MS., "Geology of India and Burma, 6th edn". College Book Store, Delhi.

[13] Gupta, AS., "Engineering behaviour and classification of weathered rocks", PhD Thesis, Indian Institute of Technology, Delhi, 1997. 